\title{
Some Characteristics of Seismic Activity in the Song Tranh 2 Reservoir, Quang Nam, Vietnam by Local Seismic Network Data
}

\author{
Nguyen Van Giang ${ }^{1,}$, , Jan Wiszniowski ${ }^{2}$, Beata Plesiewicz ${ }^{2}$, Grzegorz Lizurek ${ }^{2}$, Dinh Quoc Van ${ }^{1}$, \\ Le Quang Khoi ${ }^{1}$
}

${ }^{1}$ Institute of Geophysics, Hanoi, Vietnam

${ }^{2}$ Institute of Geophysics, PAS, Warsaw, Poland

\section{Email address:}

giangnv@igp-vast.vn (N. V. Giang), jwisz@igf.edu.pl (J. Wiszniowski)

\section{To cite this article:}

Nguyen Van Giang, Jan Wiszniowski, Beata Plesiewicz, Grzegorz Lizurek, Dinh Quoc Van, Le Quang Khoi. Some Characteristics of Seismic Activity in the Song Tranh 2 Reservoir, Quang Nam, Vietnam by Local Seismic Network Data. Earth Sciences.

Vol. 4, No. 3, 2015, pp. 101-111. doi: 10.11648/j.earth.20150403.13

\begin{abstract}
The Song Tranh 2 hydropower construction is located in the Quang Nam province (central Vietnam), it has a reservoir volume of 740 million cubic meters of water and a dam height of $96 \mathrm{~m}$. The reservoir was filled to capacity for the first time in February 2011 to about $160 \mathrm{~m}$, then it dropped to $140 \mathrm{~m}$ in July 2011. The filling of reservoir started again in August 2011 and the maximum water level of $175 \mathrm{~m}$ was reached in October 2011. Song Tranh 2 and its surrounding regions suffered from earthquakes in March 2011, it also suffered from a higher magnitude earthquake in October and November, 2012 of $M=4.6$ and 4.7 respectively. By the end of 2012, a seismic network including 6 stations was set up around the Song Tranh 2 reservoir area and a full network of 10 stations was set up by August 2013. The final seismic network is capable of detecting and locating weaker seismic earthquakes. It is also possible to calculate the extended source parameters like focal mechanism, slip direction etc. In the period from August 2013 to May 2014 about 2000 seismic events were detected, and 359 of them were localized and magnitudes were calculated. Seismic analysis and update catalogues are currently being conducted. The LocSAT application was used to locate events, to perform hypocentral inversion of the phase arrival data, to estimate the origin time, epicentral location, and depth by registered data from the VERIS network. Mechanism solutions with P-wave amplitude inversion of three events were determined. It suggests that reservoir construction is a major factor in the seismogenic process.
\end{abstract}

Keywords: Reservoir Induced Seismicity, Seismic Network, Source Parameters, Focal Mechanism, Completed Catalogue

\section{Introduction}

Earthquakes can be caused by natural processes (tectonic movement, volcanic activity etc.) or by human activities. The earthquakes associated with human activities are called seismic stimulation. Under certain suitable geological conditions anthropogenic activity can trigger or induce earthquakes [1]. The triggered or induced earthquakes are known to have occurred due to gold and coal mining [18], petroleum production, filling of artificial water reservoirs, high-pressure liquid injection into ground and natural gas production. Induced seismicity includes cases such as seismicity associated with water reservoirs, underground mining, large-scale surface quarrying, high-pressure fluid injection for geothermal power generation, oil production, solution mining and waste disposal, removal of underground fluids such as oil, gas, water, and underground explosions [22].

In some locations the Reservoir Induced Seismicity (RIS) occurs early after reservoir impoundment, while in other places the earthquake excitation occurs after a number of years when the reservoir water began to rebuild. Based on such observations, Simpson (1986) and Gupta (1992) have classified the RIS into two types: fast response type and slow response type $[12,22]$. Fast response-type is directly calculated increase in seismic analysis phase of the first water reservoir, or a sudden change in the seismic properties due to rapid changes in reservoir water levels. Examples of such reactions are the Lake Monticello, Lake Manic 3, Nurek and Kariba reservoirs. Nurek has had apparent rapid response to change after the reservoir water level. In contrast with the 
fast response RIS phenomenon, the slow response RIS events occur relatively late during reservoir filling. The examples are Aswan, Koyna and Oroville. The reservoir underwent a number of changes within the reservoir water level before the earthquake happened. In some places like Koyna, India and Lake Mead, USA; both reactions are shown in [12].

The largest reservoir impoundment - triggered earthquakes exceeded magnitude 6, while the largest earthquakes triggered by the other engineering activities was around magnitude 5. There are more than 70 examples of reservoirinduced seismicity (RIS) in the world's [11] associated earthquakes that impounded artificial water reservoirs, this was pointed out for the first time by Carder (1945) for Lake Mead in the United States [6]. India recorded a 6.3 magnitude earthquake at Koyna Dam, in December 1967. The number of reported cases of reservoir-induced earthquakes has steadily grown since then [12]. Hoa Binh reservoir, Northwest part of Vietnam, is a case of reservoir triggered seismicity where in 1989 was the largest earthquake of a magnitude of 4.9 [11]. This paper considers a case of reservoir triggered seismicity in the Song Tranh 2 reservoir located in the Quang Nam province in Central Vietnam. The Song Tranh 2 reservoir was filled to capacity for the first time in November 2010. The largest earthquake of a magnitude of 4.7 was in November $15^{\text {th }}, 2012$ and damaged buildings in the vicinity.

On the basis of co-operation research between IGPVAST and IGFPAS which was signed in 2013, the installation of seismic stations, observation, seismic monitoring and processing, analysis and interpretation of the seismological data of reservoir Song Tranh 2 area in Bac Tra My district and surrounding areas in Quang Nam province in Central Vietnam were carried out. Special emphasis was put on investigating the mechanism of eruptions and seismic hazard estimation. The first results of the monitoring activity are presented below with the preliminary interpretation of seismic pattern.

\section{Location, Geology and Tectonics of the Song Tranh 2 Reservoir}

The Song Tranh 2 (ST2) dam is one of a few dams planned to be set up on the River Tranh. Geographic co-ordinates of the dam are: $108^{\circ} 08,832^{\prime} \mathrm{E}$ and $15^{\circ} 20,013^{\prime} \mathrm{N}$. The reservoir volume is 740 million cubic meters of water and its height is 196 m (Fig.1).

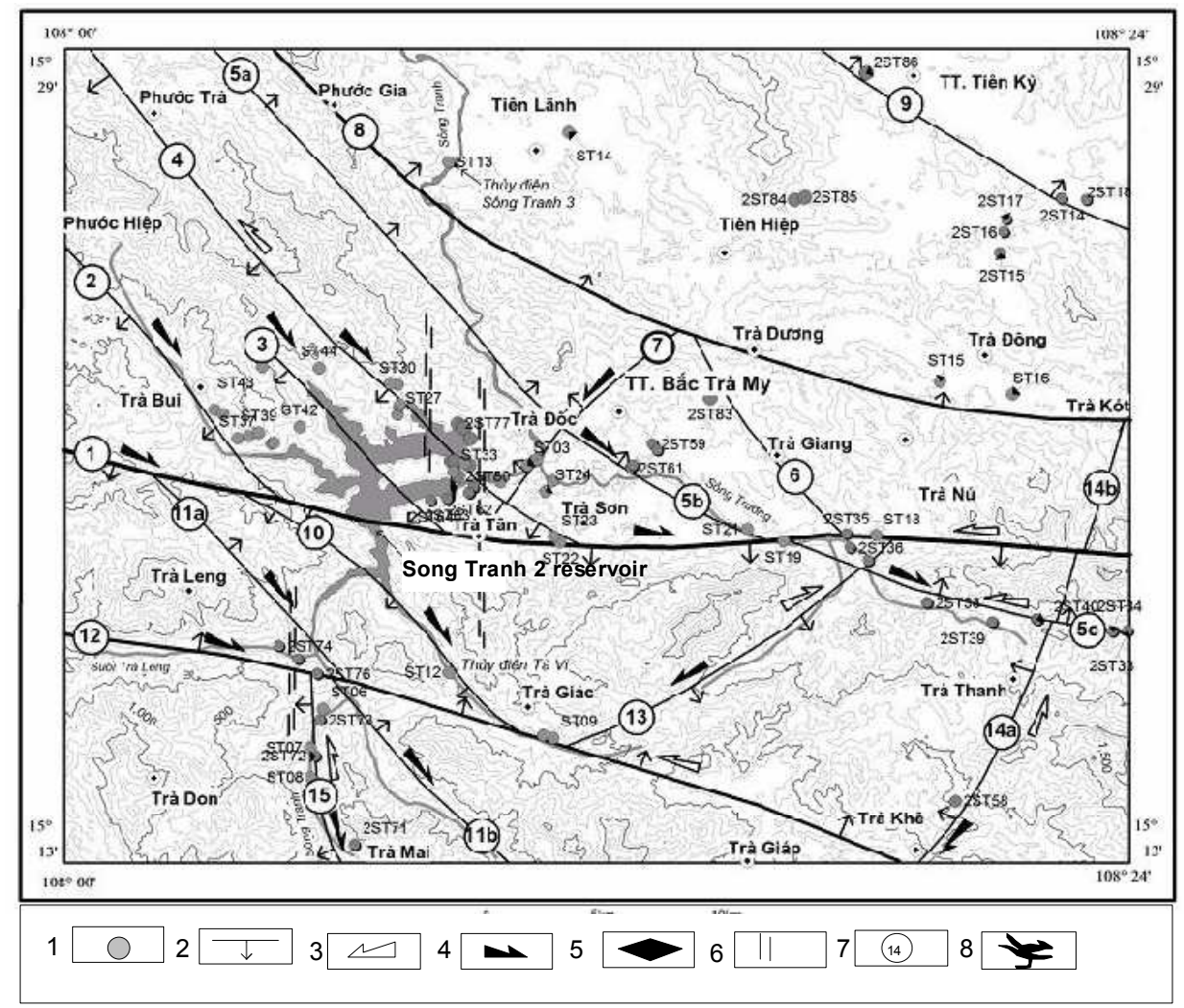

Fig. 1. Scheme of geological fault system distribution for ST2 reservoir region (taken from Hoai et al 2014 [16]). Legend: (1) Investigated point, (2) Fault and direction, (3) Tectonic movement of fault in early Cenozoic, (4) Tectonic movement of fault in later-today Cenozoic, (5) Location of Dam, (6) Fractured zone by sub-latitude direction, (7) Number of geological fault, (8) Reservoir.

Characteristics of geological background hydroelectric reservoir area ST2 are well developed and published [14, 16, 24]. The original rock in the area studied is primarily a metamorphic amphibolite general, formed during orogenic movement Indosini. It happened about $245 \div 250$ million years and the granite slab was not [21]. The lamina of the metamorphic rock had extended dominant direction in sublatitude, double parallel spot was winding and steep angles of 
plug from $45^{0}$ to descent. The ST2 was built on the metamorphic rocks of the Tra Bong and Kham Duc complex formations. Research has shown that the research area and its surroundings have undergone several stages of tectonic movements, with different distortional characteristics. There were two main ductile deformational phases with the general movement mechanism slipping by, including: early phase axis compressive strain axis, sub-latitude. Under this stress field, the NW-SE fracture activity slid to the left. In contrast, phase distortion of late had featured local compressive axial sub- meridian and enjoyed the strain axes of sub-latitude. Under the action of this stress field, the NW-SE fracture slid right; Cenozoi tectonic motion phases later had close ties with volcanic activities in Central and South Vietnam during the Neogene-Quaternary. The Dam area is located within a series of zones with split-snowboarding by NW-SE direction, which tended to raise the compression zone sub-meridian direction, which also creates a spreading trend E-W. The sublatitude and NE-SW directions faults are underdeveloped while the sub-meridian direction fault is hardly absent (Fig.1). The Dam is placed completely on the metamorphic complex gneiss Kham Duc-Nui $\mathrm{Vu}$ of regional metamorphism originated in the Ordovician.

\section{Seismic Monitoring of the Region of Dam ST2}

We can divide the recording of seismicity in ST2 area into three periods (stages).

\subsection{Period I - from January 2011 to October 2012}

In the beginning of filling the ST2 reservoir, the area was monitored by two seismic stations in Binh Dinh and Hue, but staying away from the reservoir. They recorded the earthquake in the region with a magnitude of $M>2.0$. From January 2011 to September 2012, the two stations recorded more than 100 quakes in the Bac Tra My and surroundings, having magnitudes of $\mathrm{M} 1.8 \div 4.2$. The basic parameters of the two seismic stations in Binh Dinh and Hue are presented in Tab. 1.

Tab. 1. The location and equipment for seismic stations in period I.

\begin{tabular}{|c|c|c|c|c|c|c|}
\hline \multirow{2}{*}{ No. } & \multirow{2}{*}{ Station name } & \multirow{2}{*}{ Code } & \multicolumn{2}{|c|}{ Co-ordination } & \multirow{2}{*}{ Elevation [m] } & \multirow{2}{*}{ Logger / Seismometer } \\
\hline & & & $\varphi\left[{ }^{\circ} \mathbf{N}\right]$ & $\lambda\left[^{\circ} \mathbf{E}\right]$ & & \\
\hline 1 & Binh Dinh & BDVB & 13.8645 & 109.1111 & 61 & Q330HRS / STS-2 \\
\hline 2 & Hue & HUBV & 16.4155 & 107.5689 & 20 & Q330 / Trillium-40 \\
\hline
\end{tabular}

\subsection{Period II - from October 2012 to August 2013}

The monitoring of the induced seismicity in the ST2 reservoir, from October to November 2012, the seismographic network of five stations was deployed by IGP VAST in the ST2 reservoir and vicinity. The name of the stations were Tra Doc, Tra Bui, Tra Nu, Tra Mai and Tien Lanh were also used in period III (Tab. 2). They were equipped in period II with Guralp seismometers and the SAMTAC logger and one Trillium-40 seismometer with the Q330 logger (Tra Doc station). SAMTAC recorders did not have the possibility of data transmission online. After the installation of local seismic station networks, it was possible then to get a magnitude less than 2.0. After the seismic network station was set up there, it could record a magnitude of $\mathrm{M}<2.0$ upwards.

\subsection{Period III - from August 2013 - New Joint Seismic Network}

In August 2013, installed 10 seismic stations were installed.
The common seismic network was called VERIS (Vietnam Reservoir Induced Seismicity). Stations provided by IGFPAS were equipped with short-period seismometers Lennartz LE3DLite (1s), whereas stations provided by IGPVAST were equipped with long-period seismometers Guralp CMG-6TD (30s). Signals from seismometers Lennartz were recorded by Net Data Logger (NDL), which served in the project with a sampling rate of 100 samples per second (sps) and dynamics $132 \mathrm{~dB}$. Seismometer Guralp has on-board digitizer with dynamic of $130 \mathrm{~dB}$. Seismic signal is sampled with a frequency of $100 \mathrm{sps}$. Both systems are appropriate to measure local and regional seismicity, as the main content of seismic waves comes in the range of a few $\mathrm{Hz}$, whereas stations Guralp were more suitable for the largest events in the ST2 region because of the lower frequency signal. The responses of both recording systems are shown in Fig. 2. Seismometers Lennartz 3DLite were installed in new stations, whereas seismometers Guralp replaced the previously working recorders.

Tab. 2. The location and equipment of local seismic stations of VERIS network (period III) for ST2 region (In brackets are loggers and seismometers used in period II).

\begin{tabular}{|c|c|c|c|c|c|c|}
\hline \multirow{2}{*}{ No. } & \multirow{2}{*}{ Station name } & \multirow{2}{*}{ Code } & \multicolumn{2}{|c|}{ Co-ordination } & \multirow{2}{*}{ Elevation [m] } & \multirow{2}{*}{ Logger / Seismometer } \\
\hline & & & $\varphi\left[{ }^{\circ} \mathbf{N}\right]$ & $\lambda\left[^{\circ} \mathbf{E}\right]$ & & \\
\hline 1 & Tien Ngoc & TNG & 15.4472 & 108.2038 & 97 & NDL / LE-3Dlite \\
\hline 2 & Tra Don & TDO & 15.2432 & 108.0849 & 185 & NDL / LE-3Dlite \\
\hline 3 & Tra Leng & TLE & 15.2722 & 108.0225 & 192 & NDL / LE-3Dlite \\
\hline 4 & Tra Giac & TGI & 15.2400 & 108.1756 & 328 & NDL / LE-3Dlite \\
\hline 5 & Phuoc Hiep & $\mathrm{PHI}$ & 15.4954 & 107.9776 & 56 & NDL / LE-3Dlite \\
\hline 6 & Tra Doc & TDVB & 15.3342 & 108.1634 & 113 & Guralp CMG-6TD (Q330 / Trillium-40) \\
\hline
\end{tabular}




\begin{tabular}{|c|c|c|c|c|c|c|}
\hline \multirow{2}{*}{ No. } & \multirow{2}{*}{ Station name } & \multirow{2}{*}{ Code } & \multicolumn{2}{|c|}{ Co-ordination } & \multirow{2}{*}{ Elevation [m] } & \multirow{2}{*}{ Logger / Seismometer } \\
\hline & & & $\varphi\left[{ }^{\circ} \mathbf{N}\right]$ & $\lambda\left[{ }^{\circ} \mathbf{E}\right]$ & & \\
\hline 7 & Tra Bui & TBVB & 15.3667 & 108.0503 & 224 & Guralp CMG-6TD (SAMTAG / Guralp) \\
\hline 8 & $\mathrm{Tra} \mathrm{Nu}$ & TNVB & 15.3564 & 108.3268 & 126 & Guralp CMG-6TD (SAMTAG / Guralp) \\
\hline 9 & Tra Mai & TMVB & 15.1480 & 108.1202 & 202 & Guralp CMG-6TD (SAMTAG / Guralp) \\
\hline 10 & Tien Lanh & TLVB & 15.4958 & 108.1200 & 325 & Guralp CMG-6TD (SAMTAG / Guralp) \\
\hline
\end{tabular}

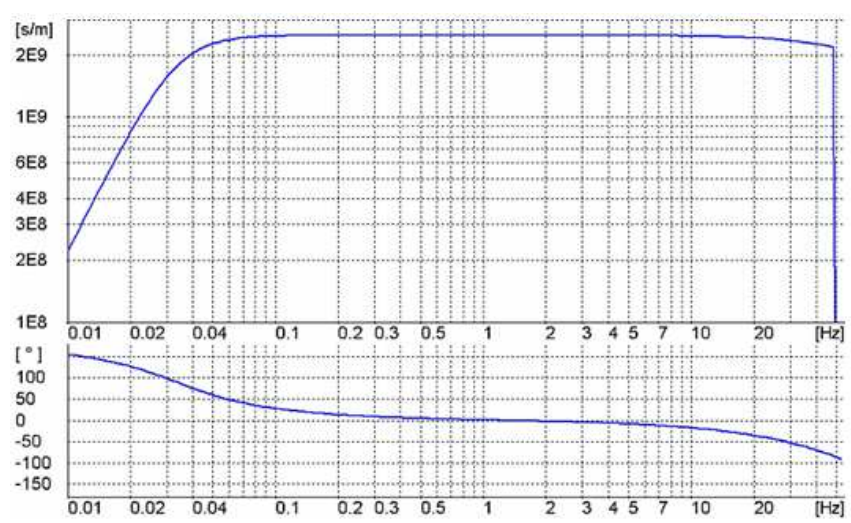

a)

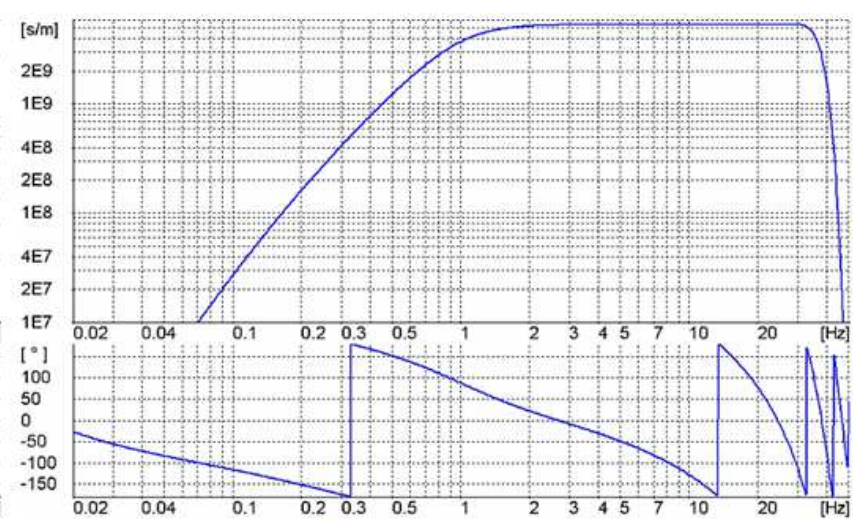

b)

Fig. 2. The frequency-amplitude-phase response of: a) the Guralp CMG-6TD seismometer and b) the Lennartz LE-3Dlite seismometer with the NDL recorder.

The choice of location for installed local seismic stations in this region was preceded by Ground Penetrating Radar (GPR) measurements [10]. The goal of the investigation was to find the location and foundation for stations on the bedrock. The GPR measurement helped in assessing the cohesiveness of the sub-stratum, whether the rock is fissured or separated from the bedrock. Good foundation of a seismic stations allows noise reduction and enhances the early detection local seismic events. It is important, because there is the need for stations to be located in order to ensure security in neighborhoods. The basement investigation carried out by $100 \mathrm{MHz}$ frequency antennas Pulse Ekko
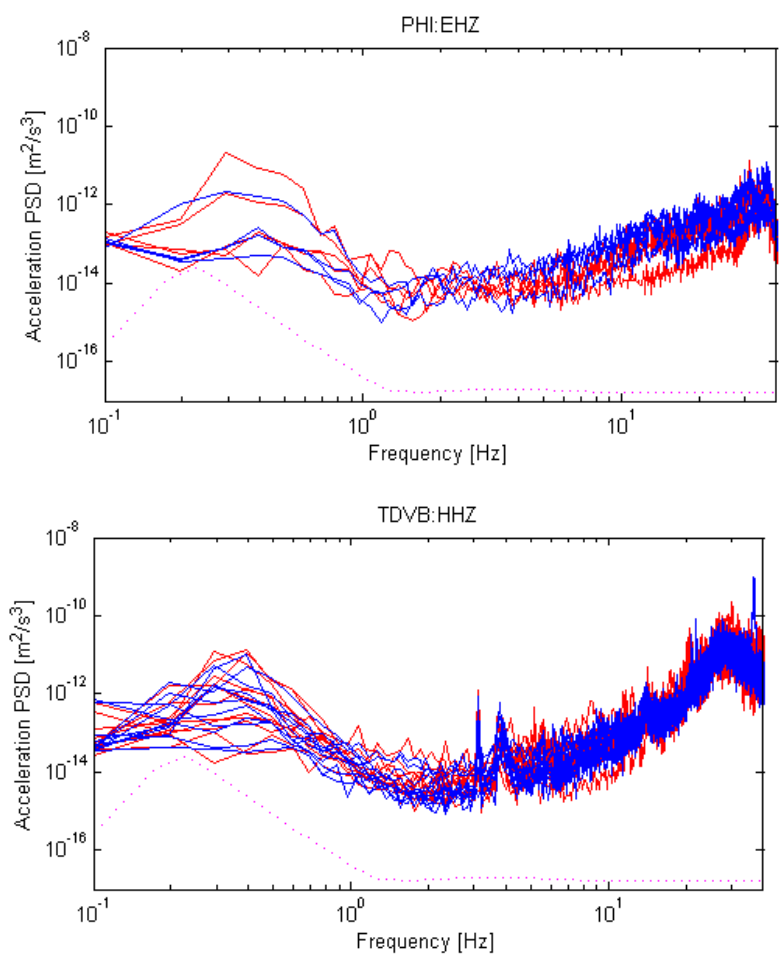

100A Geological System for all 10 local seismic stations: Tra Doc, Tra Bui, Tra Nu, Tra Mai, Tra Don, Tra Leng, Tra Giac, Phuoc Hiep, Tien Lanh and Tien Ngoc. The interpretation of GPR radagrams showed good quality of data and nearsurface geological structure consists of 4 layers where the three first layers are fractured from surface to depth of $3 \mathrm{~m}$ and the last layer is slightly fractured and consolidated to $10 \mathrm{~m}$ of depth. The Power Spectral Densities (PSD) of seismic noises are presented in Fig. 3. We didn't notice differences in noise between day and night and between dry and rainy seasons.
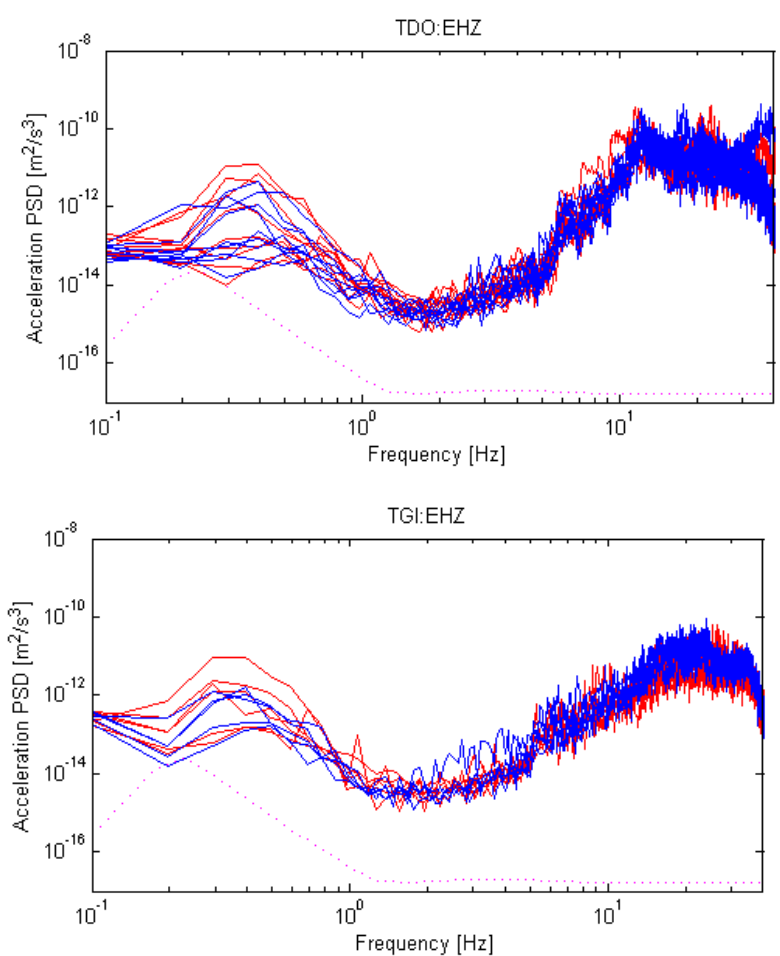

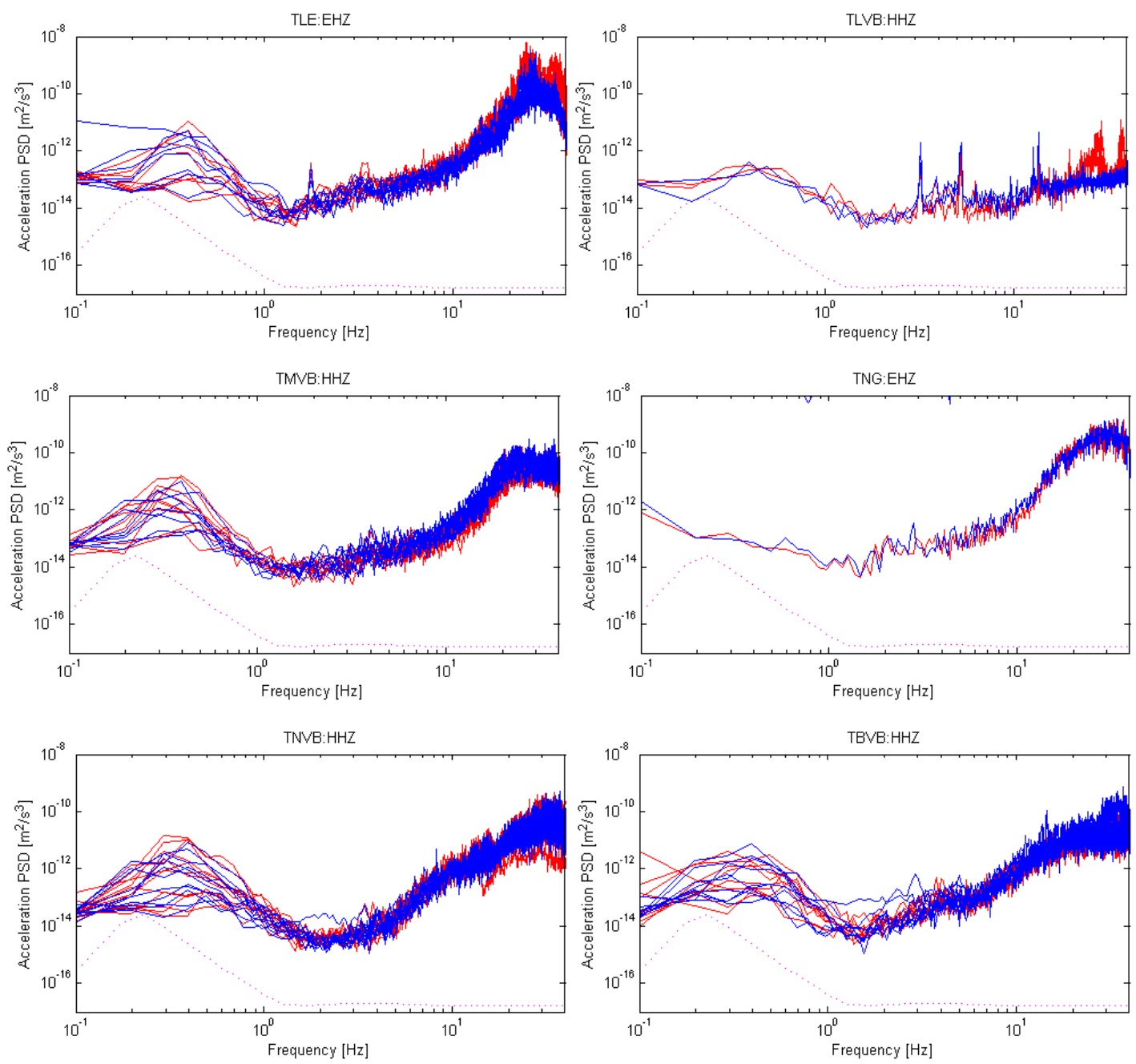

Fig. 3. The Power Spectral Densities (PSD) of seismic noises for local seismic stations of ST2 networks. In most stations the PSD is taken from both rainy and dry seasons. The electronic red lines describe PSD in day whereas blue ones show noise at night. The dotted line is the PSD of Peterson's (1993) Low Noise Model [18].

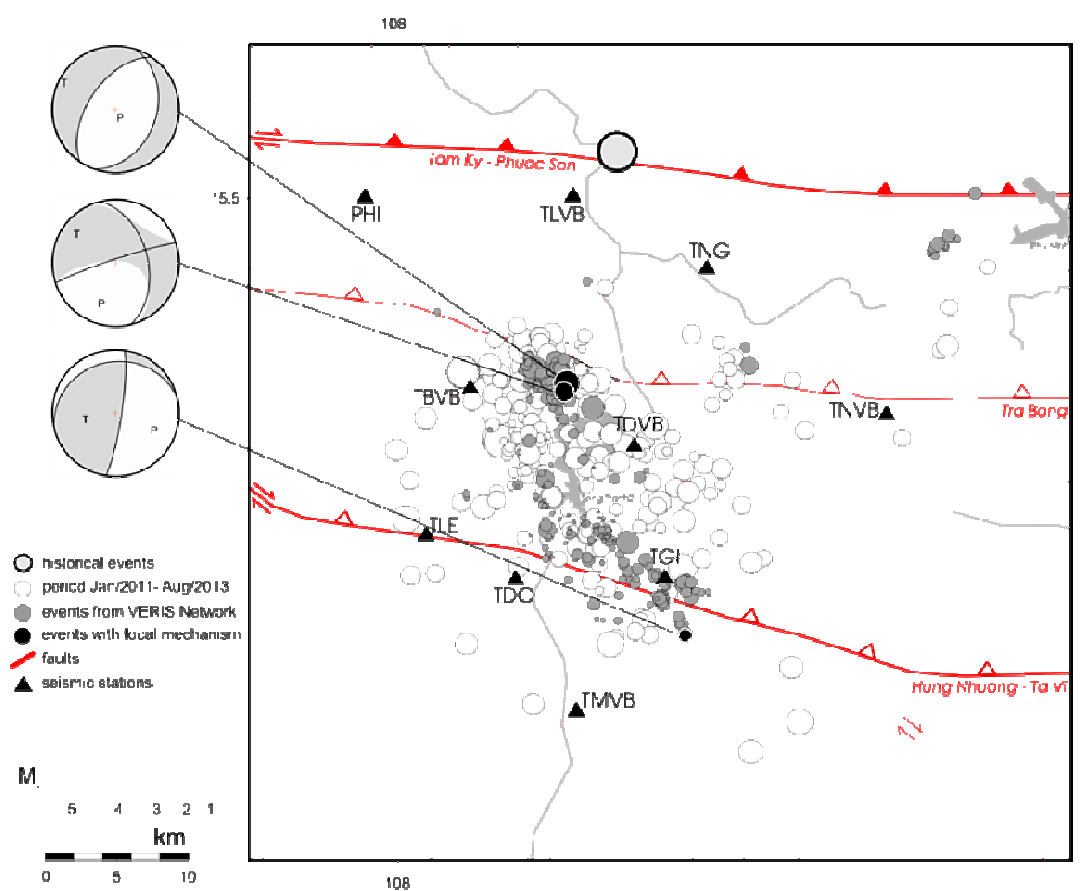

Fig. 4. Location of historical events and events from the period 2011-2014 grouped around the ST2 reservoir. 
The final seismic network increased earlier possibilities of detection and location of weaker seismic earthquakes. It is also possible to calculate extended source parameters like focal mechanism, slip direction etc. Within the period from August 2013 to May 2014 about 2000 seismic events were detected, and 359 of them were localized and magnitudes were calculated (Fig. 4.). Seismic bulletins and catalogues of seismic monitoring in the ST2 region contain movements since August 2013. Seismic analysis and update catalogues are currently being conducted. The LocSAT application was used to locate events registered from the VERIS network. LocSAT with the IASP91 travel-time tables are used to perform hypocentral inversion of the phase arrival data. LocSAT estimates the origin time, epicentral location, and depth as an iterative least-squares inversion of travel time, slowness, and/or azimuth measurements [3,4].

Earthquakes registered in the period between January 2011 and July 2013 were of magnitude $1 \leq \mathrm{M}_{\mathrm{L}} \leq 4$. After the expansion of seismic networks in the ST2 region the threshold of completed recorded events were from $\mathrm{M}_{\mathrm{L}}=0.3$. Earthquakes from August 2013 to May 2014 were recorded by the VERIS network in several places to the north-west and south-east from the ST2 reservoir. While these groupings were not visible from January 2011 to August 2013, because it was a larger location. We can specify two main groups of epicenters of earthquakes in the ST2 area, in the northern part of the reservoir near the Tra Bong thrust and the epicenters in the southern part arranged in a line sub-latitude to the likely Hung Nhuong - Ta Vi thrust.

\section{Completed Catalogues for the Veris Network - Period III}

Magnitude of completed $\left(\mathrm{M}_{\mathrm{C}}\right)$ earthquake catalogues were the lowest magnitude at which all the earthquakes were detected in selected space and time volume. The completed catalogues were estimated on a frequency-magnitude distribution (FMD) of detected events in the selected region as well as by techniques [19]: Maximum Curvature (MAXC) [27], Entire Magnitude Range (EMR) [25,28] and study of the b-value stability of Gutenberg-Richter model [13] as a function of cut off magnitude (MBS) [5].

The Maximum Curvature method estimates $M_{C}$ as the point of the maximum curvature by computing the maximum value of the first derivative of the frequency-magnitude curve (cumulated FMD). In practice, this matches the group of magnitudes with the highest frequency of events in the FMD. This technique requires fewer events than other techniques to reach a stable result, however it underestimates the $M_{C}$ value sometimes [27].

The EMR technique is used to estimate the $\mathrm{M}_{\mathrm{C}}$ the entire magnitude range with events below the $\mathrm{M}_{\mathrm{C}}$. Woessner and Wiemer (2005) [28] proposed a model consisting of two parts: the Gutenberg-Richter law for the complete part, and the cumulative normal distribution for the incomplete part of the
FMD.

Cao and Gao (2002) [5] estimated Mc using the stability of the $b$-value as a function of cut-off magnitude $\mathrm{M}_{\mathrm{Co}}$, named as MBS by Woessner and Wiemer (2005) [28]. The $M_{C}$ is defined as the magnitude for which the changes in b-value $(\Delta \mathrm{b})$ is smaller than 0.03 . It is based on an assumption that the estimation of $b$ increases for $\mathrm{M}_{\mathrm{Co}}<\mathrm{M}_{\mathrm{C}}$ and remains constant for $\mathrm{M}_{\mathrm{Co}}>\mathrm{M}_{\mathrm{C}}$. This method doesn't produce good results in case of high variability of the FMD. Woessner and Wiemer (2005) [28] used the b-value uncertainty $\delta$ b according to Shi and Bolt (1982) as criterion:

$$
\delta b=2.3 b^{2} \sqrt{\frac{\sum_{i=1}^{N}\left(M_{i}-\langle M\rangle\right)^{2}}{N(N-1)}}
$$

where $\langle\mathrm{M}\rangle$ is the mean magnitude and $\mathrm{N}$ is the number of events. In case of events in the Podhale region, the variability of the FMD is rather high, because of a small number of events.

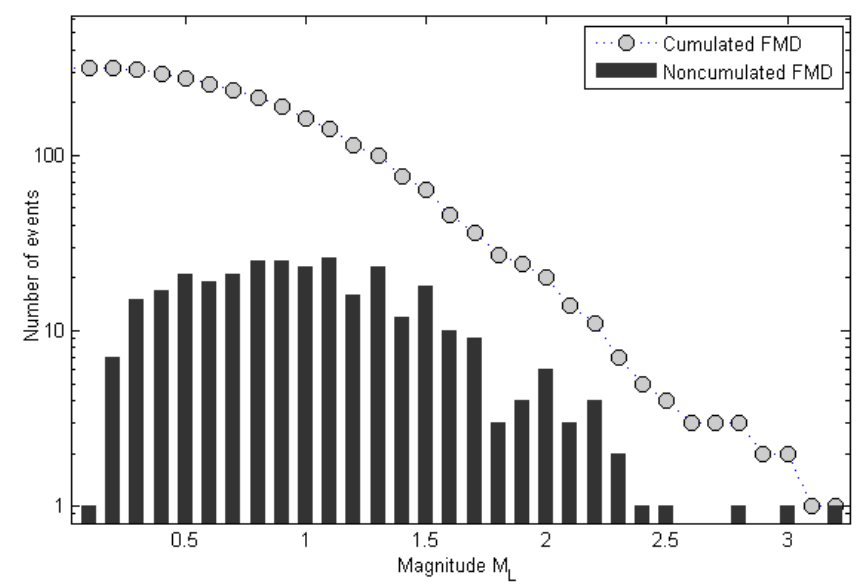

Fig. 5. The FMD of events recoded in ST2 region in period 2013 - 2014.

In the period from August 2013 to May 2014 VERIS seismic network in central Vietnam recorded about 2000 earthquakes where about 350 were located. The values of magnitudes $\mathrm{M}_{\mathrm{C}}$ of completed catalogues were calculated by different methods and minimum magnitude $\left(\mathrm{M}_{\min }\right)$ are presented in Tab. 3. Based on these values and based on the shape of the FMD of events recorded in years 2013-2014 the $\mathrm{M}_{\mathrm{C}}$ was assumed as a value 1.1 (Fig. 5.) not dear more recorded events are less than $\mathrm{M}_{\mathrm{C}}$.

Tab. 3. Magnitudes of completed catalogues $\left(M_{C}\right)$ of events in the period 2013-2014 estimated by various methods.

\begin{tabular}{ll}
\hline Technique & $\mathbf{M}_{\mathbf{C}}$ \\
\hline MAXC & 0.8 \\
EMR & 1.1 \\
MBS & 0.22 \\
$\mathrm{M}_{\text {min }}$ & 0.12 \\
\hline
\end{tabular}




\section{Seismic Activity Caused by the Filling of the ST2 Reservoir}

The filling of the ST2 reservoir started in November 2010. The water level began to increase slowly from about $153 \mathrm{~m}$ in January 2011 to about $159.4 \mathrm{~m}$ in February 2011 and then it dropped to around $140 \mathrm{~m}$ in July 2011. The filling of the reservoir started again in August, 2011. In October, 2011, the maximum water level of $175 \mathrm{~m}$ was reached. It is also the highest level of reservoir activity till date. The water level of the reservoir was kept around $175 \mathrm{~m}$ until February 2012, when it was quickly dropped to the level of $157.64 \mathrm{~m}$. In May, 2012, it was further decreased to $139.3 \mathrm{~m}$. After which it was kept about $140 \mathrm{~m}$ to the end of September 2013. The water level began to increase with one sharp decline in November to the level of $149 \mathrm{~m}$. The water level reached about $165.6 \mathrm{~m}$ in the beginning of 2014. Fig. 6 shows the relationship between the reservoir water level variation and earthquakes.

The natural seismic activity of the ST2 and its surroundings was very low. From the earthquake sources such as operational history, international data and data recorded by seismic stations in Central Vietnam, it was found that between 1775 to 1992 only 13 eruptions were occured in this area. However, there was an earthquake with magnitude of 4.7 in 1715 which was located near the ST2 reservoir (Fig.4) [24].

From the end of 2010, through analyses of earthquakes recorded by 2 Vietnam national seismic stations located in Binh Dinh and Hue (about 160-120 km far from ST2), it was found that several earthquakes appeared, whose epicenters were located in the province of Quang Nam. Until early 2011, the frequency of earthquakes in this area increased significantly. The occurrence of noticeable earthquakes in the ST2 area and its vicinity started in March, 2011 (Fig.6d). Especially, two quite strong eruptions occurred on October $22^{\text {nd }}$ and November $15^{\text {th }}, 2012$, with magnitude $\mathrm{M}_{\mathrm{L}}=4.6$ and 4.7 respectively, which was felt by the inhabitants and damaged buildings in Bac Tra My area. On November 2012 the number of events in the 10-day period was high with a decreasing trend. Seismic activity is still is in progress with an increase in the water level to $165 \mathrm{~m}$.
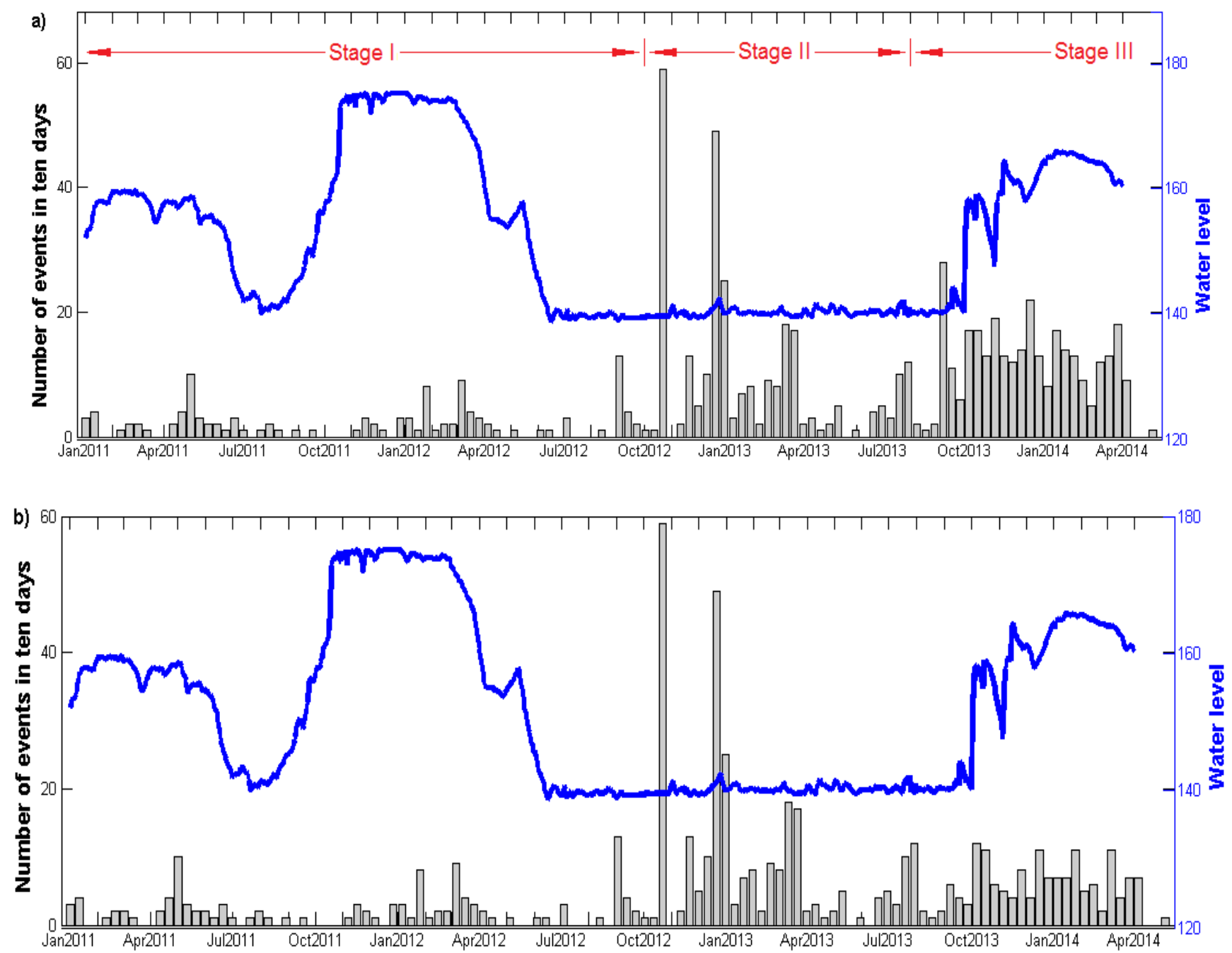

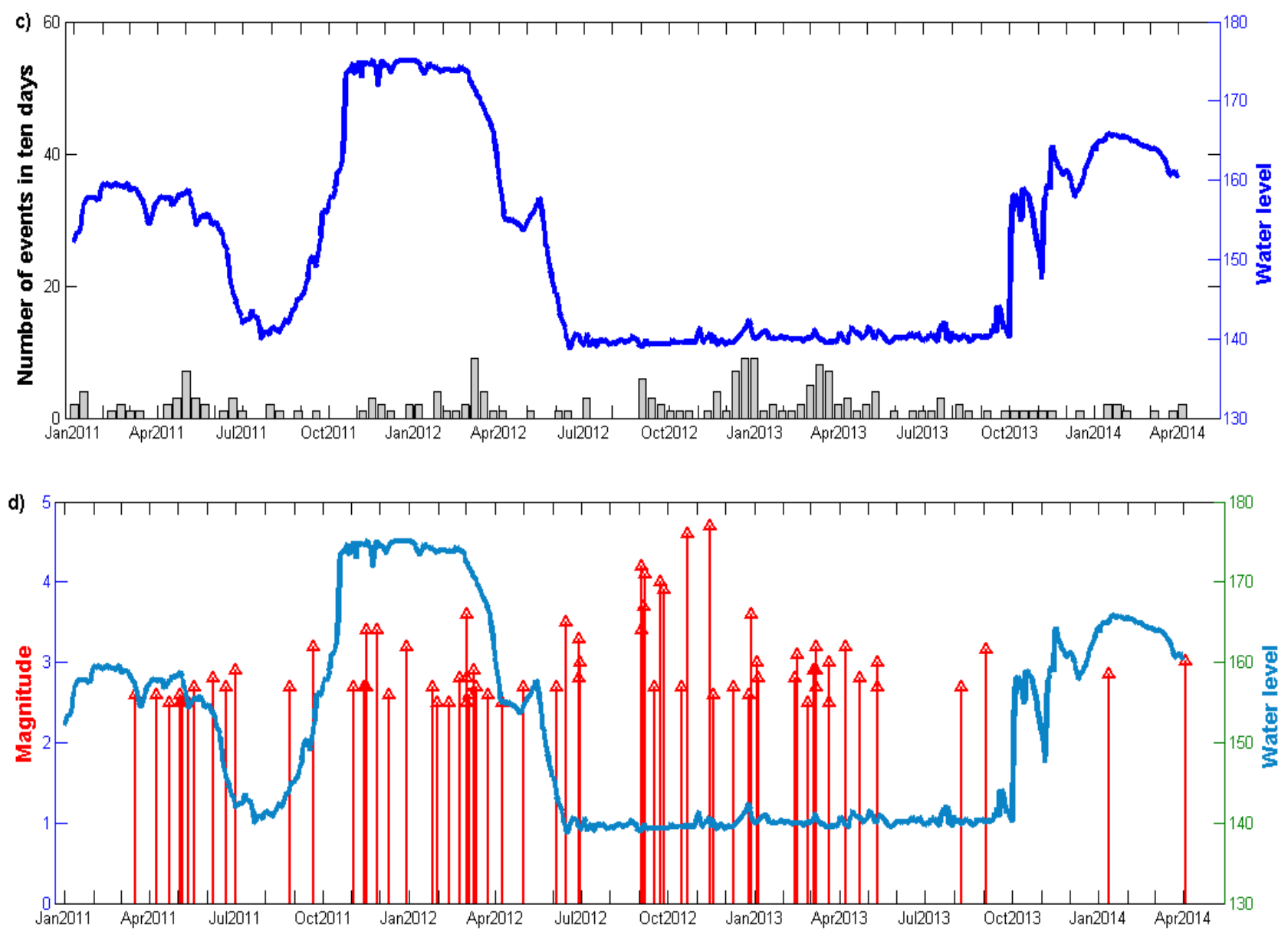

Fig. 6. The level of the water in the ST2 reservoir and seismic activity around the region in the period of January 2011 to April 2014 with: (a) number of all localized events in 10 days period, (b) number of events in 10 days period and magnitude higher than 1, (c) number of events in 10 days period and magnitude higher than 2, (d) events with magnitude higher than 2.5 .

Fig. 6 a, b and c, shows that each stage increased earlier possibilities of detecting and locating smaller seismic earthquakes. These figures show improvement of seismic monitoring of the ST2 whereas Fig. $6 \mathrm{c}$ and d shows the relationship between water level and seismicity for all the periods. The water level of reservoirs was tentatively divided into three cycles of high levels. During the first cycle when the water level reached the high of $160 \mathrm{~m}$ in February 2011, the frequency of earthquakes increased especially in times when the water level started falling in May 2011. This phenomenon also occurred in second cycles of high water from January 2011 to March 2012, when earthquakes began to appear the water level reached a high of $175 \mathrm{~m}$ with dense occurrence of events when the water level dropped from 173 $\mathrm{m}$ to $170 \mathrm{~m}$ in March 2012. During the third cycle from October 2013 seismic activity was relatively low, although the research continued. It suggests that seismicity is related to drawdown levels of the reservoir rather than to higher water levels like the lake in the case of Tehri Dam in India [8]. However, the highest density of earthquakes and the strongest eruptions appeared within the period from August 2012 to February 2013 when the water level was low. Additionally, the decision to reduce the level of water is often caused by increasing the seismicity.

\section{The Focal Mechanism of Events: September $3^{\text {rd }}, 2013$ with $M_{1}=3.2$, October $24^{\text {th }}, 2013$ with $M_{1}=2.3$, October 31 ${ }^{\text {st }}, 2013$ with $M_{1}=1.8$}

Calculations of the moment tensor from the VERIS network records were performed by FOCI software 3.0 [17]. The inversion of the $\mathrm{P}$ wave amplitude was performed in time domain approach $[2,26]$. The registered first onsets were: Direct $\mathrm{P}$ wave according to the velocity model of the ST2 area. The velocities determined for the waves were: Direct wave $5 \mathrm{~km} / \mathrm{s}$. The Direct waves were recorded at 8 stations on the VERIS network. The input parameters are the amplitude and polarity information on the first P-wave displacement pulses. According to Fitch et al. (1980) [9] the recorded displacement for the vertical component of the Pwave phase is:

$$
U_{z}^{P}(x, t)=\frac{1}{4 \pi \rho \alpha^{3} r}\left[\bar{\gamma} M \dot{s}\left(t-\frac{r}{\alpha}\right) \bar{\gamma}\right] l_{z},
$$


Where $\rho$ is the average density, $r$ is the source-receiver distance, $\alpha$ is the average velocity of $P$ wave, $M$ is the seismic moment, $1_{z}$ is the cosine of the angle of the incidence and is the take-off angle. The Source Time Function (STF) was based on the Haskell's source model [15]:

$$
\dot{s}=\begin{array}{cc}
1 / T, & 0<t<T \\
0, & \text { elsewhere }
\end{array}
$$

where $\mathrm{T}$ is rupture time.

The moment tensor is obtained by solution of a set of $\mathrm{N}$ equations of type (1). From Awad and Kwiatek, 2005 [2], Cesca et al., 2010 [7], we have $U=G M$, where $M$ is moment tensor and $\mathrm{G}$ is Green function, $\mathrm{U}$ is the displacement matrix. Inversion of this formula by solving it with use of the (1) allows to find moment tensor. Determination of the Moment tensor is realized by finding the best solution of (GM$\mathrm{U})^{\wedge} 2=\min$., and $\mathrm{U}$ is the displacement amplitude calculated with eq. (1).

Due to the six independent elements of the moment tensor there must be at least six such equations, but the more, the better. The deviatory, pure shear and full moment tensor was calculated using the $\mathrm{L}_{2}$ norm as a measure of the misfit [2, 26]. The results of inversion are presented in Tab. 4 and Fig. 7. The focal sphere azimuthal coverage was sparse and number of available recordings was at the limit of the methodological requirements, which obviously influenced the inversion results. Nevertheless the first three focal mechanism solutions are a good first insight into the focal and tectonic properties of the process inducing seismic events in the vicinity of the ST2.

Source mechanism of September $3^{\text {rd }}, 2013$ event is a normal fault with strike azimuth NNE-SSE and moderate dip angle about 40-50 degrees (Fig.7 ). Nodal plane orientations are sub-latitude to the Tra Bong thrusting movement direction, but perpendicular to the strike of this main

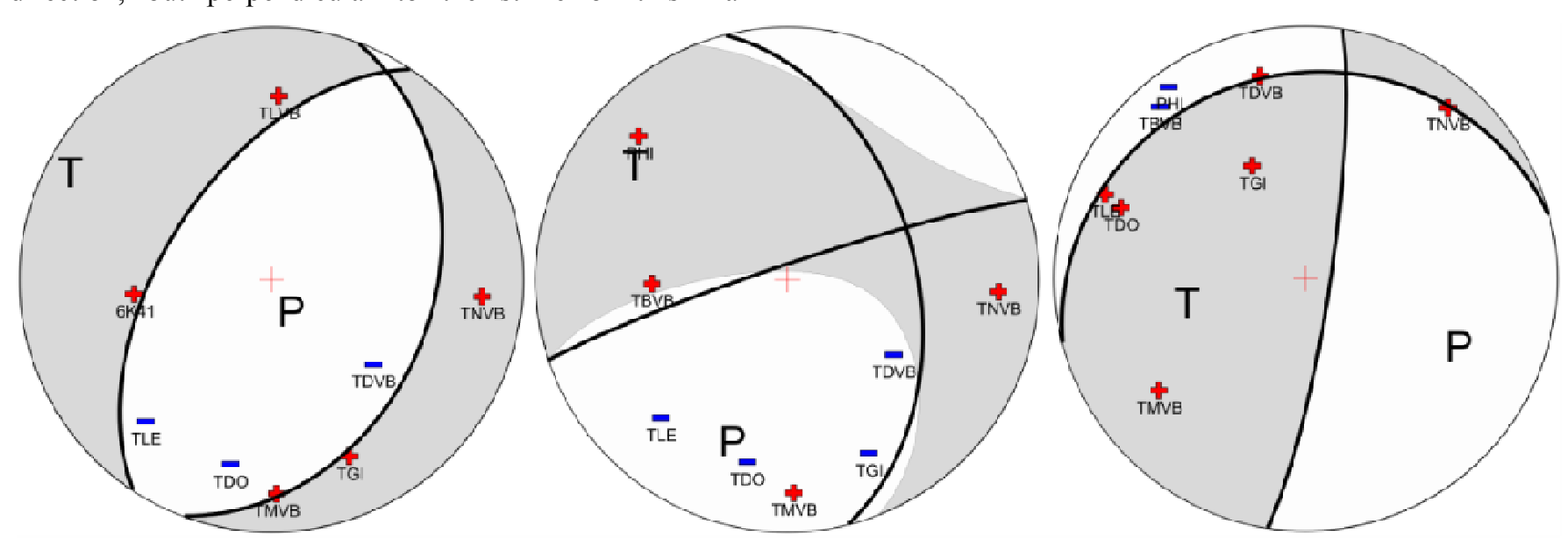

Fig. 7. Mechanism solutions with P-wave amplitude inversion of three events from the left: September $3^{\text {rd }}, 2013 M_{L}=3.2$, October $24^{\text {th }}, 2013 M_{L}=2.3$, October $31^{\text {st }}, 2013 M_{L}=1.8$. The codes and signs denote the station location and polarization on focal sphere. All solutions are presented as a Lambert azimuthal equal-area projection on upper hemisphere Schmidt net. discontinuity. In the area of the event location the main discontinuities are not in agreement with the nodal planes' orientation. Moreover, the main stress regime indicates strike-slip faulting, while the inversion results indicate the normal faulting. The tension axis orientation are similar to the main strike slip stress pattern in this area, but the polarities and amplitudes of the first $\mathrm{P}$-wave pulses determine the focal mechanism results as a normal fault. The quality of the solution is limited by the number of stations available and their azimuthal coverage. There are only 8 stations with good signal to noise ratio, which were used in inversion. The azimuthal coverage was good in the southern half of the focal sphere, but only one station was available in the northern half of the focal sphere.

Source mechanism of October $24^{\text {th }}, 2013$ event is a strikeslip fault with a NEE-SWW or NNW-SSE strike. The latter strike orientation is parallel to the local fault connecting the two main discontinuities Tra Bong and Hung Nhuong- Ta Vi. The azimuthal station coverage of the focal sphere was poor in the NW quadrant and reasonably well in the southern half. The event was located near the location of the September $3^{\text {rd }}$, 2013 eruption, but their focal mechanism and fault plane solutions differ.

Source mechanism obtained for the October $31^{\text {st }}, 2013$ event was a reverse fault with strike almost N-S or W-E. The second nodal plane orientation is almost similar to the Hung Nhuong -Ta Vi thrust, but the main regime of this area is strike-slip, which is not in agreement with the obtained focal mechanism. Again the azimuthal station coverage was not good, especially in the SW quadrant of the focal sphere, where even a single station was not available, while 6 out of 8 available stations covered the NW quadrant.

Obtained results are not sufficient for any general conclusions about the stress or tectonic regime of the process leading to the seismicity of the ST2 reservoir vicinity. 
Tab. 4. Seismic Moment, Moment Magnitude and nodal planes of the three seismic events calculated from VERIS network.

\begin{tabular}{|c|c|c|c|c|}
\hline Event & Seismic Moment [Nm] & $\mathbf{M}_{\mathrm{w}}$ & Nodal plane A & Nodal plane B \\
\hline September $3^{\text {rd }}, 2013$ & $5.01 \cdot 10^{13}$ & 3.1 & $33^{\circ} / 55^{\circ} /-82^{\circ}$ & $200^{\circ} / 36^{\circ} /-101^{\circ}$ \\
\hline October $24^{\text {th }}, 2013$ & $1.44 \cdot 10^{12}$ & 2.1 & $76^{\circ} / 89^{\circ} /-51^{\circ}$ & $167^{\circ} / 39^{\circ} /-179^{\circ}$ \\
\hline October $31^{\text {st }}, 2013$ & $2.85 \cdot 10^{12}$ & 2.2 & $190^{\circ} / 78^{\circ} / 72^{\circ}$ & $69^{\circ} / 22^{\circ} / 147^{\circ}$ \\
\hline
\end{tabular}

\section{Conclusions}

Before 2010, when ST2 reservoir was not yet in operation, earthquake activity in the area was low, but from November 2010, when the reservoir was full of water, the earthquake occurence increased, most notable were the large two quakes 4.6 and 4.7 Richter on November 2012. This event is the basis to link past earthquake-causing sources related to reservoir stimulation earthquake here. The seismicity is clearly triggered by the ST2 reservoir as the region had been practically aseismic before the dam was built.

The characteristics of earthquake activity stimulated reservoir area are the initial results based on earthquake records data string is not complete by the early use of the reservoir. Since the local earthquake recording stations network was put into operation, the data source record was able to really handle, analyze which results show seriousness of earthquakes in this area concentrated in the protection system of the fault Tra Bong and Hung Nhuong-Ta Vi along in the direction of NNW-EES and the cause of the increased activities of the earthquakes are related with respect to the operation of the ST2 reservoir. It also suggests that reservoir construction is a major factor in the seismogenic process.

\section{Acknowledgments}

This research was supported by Institute of Geophysics PAS (IGFPAS) and Institute of Geophysics VAST (IGPVAST) in period 2012-2014.

\section{References}

[1] Atkinson Gail M., Hadi Ghofrani and Karen Assatourians, 2015. Impact of Induced Seismicity on the Evaluation of Seismic Hazard: Some Preliminary Considerations. Seismological Research Letters, v. 86, p. 1009-1021, DOI:10.1785/0220140204.

[2] Awad H., Kwiatek G., 2005. Focal mechanism of earthquakes from June 1987 swarm in Aswan,Egypt, calculated by the moment tensor inversion. Acta Geophys. Pol. Vol. 53, No. 3, 275-291.

[3] Bratt S. R., Bache T. C., 1988. Locating events with a sparse network of regional arrays. Bulletin Seism. Soc. Am., Vol. 78, 780-798.

[4] Bratt S. R., Nagy W., 1991. The LocSAT program, Science Applications International Corporation, San Diego.

[5] Cao A. M. and Gao S. S., 2002. Temporal variations of seismic b-values beneath northeastern Japan Island arc. Geophys. Res. Lett., 29, 9.
[6] Carder, D.S.,1945. Seismic investigations in the Boulder Dam area, 1940-1944 and the influence of reservoir loading on local earthquake activity. Bull. Seismol. Soc. Am. 35, 4, 175192.

[7] Cesca S., S. Heimann, K. Stammler, T. Dahm, 2010. Automated procedure for point and kinematic source inversion at regional distances. J. Geophys. Res. 115, B6, B06304, DOI: 10.1029/2009JB006450.

[8] Choudhury, S., Gautam, P.K., Paul, A., 2013. Seismicity and Reservoir Induced Crustal Motion Study around the Tehri Dam, India. Acta Geophysica, 61, 923 - 934. DOI:2478/s11600-013-0125-1.

[9] Fitch T. J., McCowan D. W., Shields M. W., 1980. Estimation of seismic moment tensor from teleseismic body wave data with application to intraplate and mantle earthquakes. J. Geophys. Res. 85, 3817-3828.

[10] Giang N.V., G.Marquis, L.H.Minh. 2010. EM and GPR investigations of contaminant spread around the Hoc Mon waste site, Vietnam. Acta Geophys. DOI: 10.2478/s11600010-0023-8; Vol. 58, 6, 1040 - 1055.

[11] Gupta H.K., 2011. Artificial Water Reservoir Triggered Earthquakes in Encyclopedia of Solid Earth Geophysics, Springer, 15-24.

[12] Gupta H.K., 1992. Reservoir Induced Earthquakes. Elsevier Scientific Publishing Company, Amsterdam, 229pp.

[13] Gutenberg B. and Richter C. F., 1944. Frequency of earthquakes in California. Bull. Seismol. Soc. Am. 34, 185188.

[14] Hai T. T., Khin Zaw., Jacqueline A.Halpin., T. Manaka., Sebastien Meffre.,C. Lai., Y. Lee., Hai V.L., Sang D., 2014. The Tam Ky-Phuoc Son Shear Zone in central Vietnam: Tectonic and metallogenic implications. Gondwana Research., Vol.26, 144-164.

[15] Haskell N. A., 1953. The dispersion of surface waves in multilayered media. Bull. Seism. Soc. Am. 43, 17-34.

[16] Hoai L. T.T., N. V. Vuong, B. V. Dong, 2014. Fault and Faulting Characteristics in Relationship with Reservoir Triggered Earthquakes in the Song Tranh 2 Hydropower Plan, Bac Tra My, district, Quang Nam province. NU Hanoi Journal of Science - Natural Science and Technology, vol.30 (2S) p. 21-32 (in Vietnamese, abstract in English).

[17] Kwiatek G., 2013. http://www.sejsmologiagornicza.pl/projekty/foci (in Polish).

[18] Lizurek G., L. Rudzinski and B. Plesiewicz, 2015. Mining induced seismic event on an inactive fault. Acta Geophy., vol. 63, No.1, 176-200, DOI: 10.2478/s11600-014-0249-y

[19] Mignan A. and Woessner J., 2012. Estimating the magnitude of completeness in earthquake catalogs, Community Online Resource for Statistical Seismicity Analysis, available at link: http://www.corssa.org. 
[20] Peterson, J., 1993. Observations and modeling of seismic background noise. U.S. Geol. Surv. Open File Rep., 93-322.

[21] Roger F. , H. Maluski, A. Leyreloup, C. Lepvrier, P. T. Thi., 2007. U-Pb dating of high temperature metamorphic episodes in the Kon Tum Massif (Vietnam). Journal of Asian Earth Sciences, Vol.30, Issues 3-4, 15, 565-572.

[22] Simpson D.W., 1986. Triggered earthquakes. Annu. Rev. Earth Planet. Sci., 14, 21-42.

[23] Simpson D.W., Leith W.S., Scholz C.H., 1988. Two types of reservoir-induced seismicity. Bull. Seismol. Soc. Am. 78(6), 2025-2040.

[24] Thuy N.N., P.V.Phach, V. V.Chinh, L.H.Minh, P.D.Nguyen, 2003. Report on estimation of the seismic design for the Song Tranh 2 hydropower construction. Archives in the Institute of Geophysics, VAST, Hanoi (in Vietnamese).
[25] Trojanowski J.,B. Plesiewicz and J. Wiszniowski, 2015. Seismic monitoring of Poland- Description and results of temporary seismic project with mobile seismic network. Acta Geophy., vol.63, No.1, 17-44, DOI: 10.2478/s11600-0140255-0.

[26] Wiejacz P., 1992. Calculation of seismic moment tensor for mine tremors from the Legnica-Głogów Copper Basin. Acta Geophys. Pol. Vol. 40, 103-122.

[27] Wiemer S. and Wyss M., 2000. Minimum magnitude of complete reporting in earthquake catalogs: examples from Alaska, the Western United States, and Japan. Bull. Seismol. Soc. Am., 90, 859-869.

[28] Woessner J. and Wiemer S., 2005. Assessing the quality of earthquake catalogues: Estimating the magnitude of completeness and its uncertainty, Bull. Seismol. Soc. Am., 95, 684-698. 